\title{
Effects of intravitreal ranibizumab on the untreated eye and systemic gene expression profile in age-related macular degeneration
}

\author{
Katarzyna Michalska- \\ Małecka ${ }^{1,2}$ \\ Adam Kabiesz ${ }^{2}$ \\ Malgorzata W Kimsa ${ }^{3}$ \\ Barbara Strzałka-Mrozik ${ }^{3}$ \\ Maria Formińska-Kapuścik ${ }^{2,4}$ \\ Malgorzata Nita ${ }^{5}$ \\ Urszula Mazurek ${ }^{3}$ \\ 'Clinical Department of \\ Ophthalmology, Medical University of \\ Silesia, Katowice, Poland; ${ }^{2}$ University \\ Center for Ophthalmology and \\ Oncology, Independent Public Clinical \\ Hospital, Medical University of Silesia, \\ Katowice, Poland; ${ }^{3}$ Department of \\ Molecular Biology, School of Pharmacy \\ with the Division of Laboratory \\ Medicine in Sosnowiec, Medical \\ University of Silesia, Katowice, Poland; \\ ${ }^{4}$ Clinical Department of Children \\ Ophthalmology, Medical University of \\ Silesia, Katowice, Poland; ${ }^{5}$ Domestic \\ and Specialized Medicine Centre \\ "Dilmed", Katowice, Poland
}

Correspondence: Katarzyna MichalskaMałecka

Clinical Department of Ophthalmology,

Medical University of Silesia, Ceglana

Street 35, Katowice, Poland

Tel +48 32358 I 280

Email k.michalska.malecka@gmail.com
This article was published in the following Dove Press journal:

Clinical Interventions in Aging

24 March 2016

Number of times this article has been viewed

\begin{abstract}
The purpose of this study was to evaluate the systemic effects of intravitreal ranibizumab (Lucentis) treatment in patients with neovascular age-related macular degeneration (AMD). The impact of intravitreal ranibizumab injections on central retinal thickness (CRT) of treated and contralateral untreated eyes, and differences in gene expression patterns in the peripheral blood mononuclear cells were analyzed. The study included 29 patients aged 50 years old and over with diagnosed neovascular AMD. The treatment was defined as $0.5 \mathrm{mg}$ of ranibizumab injected intravitreally in the form of one injection every month during the period of 3 months. CRT was measured by optical coherence tomography. The gene expression profile was assigned using oligonucleotide microarrays of Affymetrix HG-U133A. Studies have shown that there was a change of CRT between treated and untreated eyes, and there were differences in CRT at baseline and after 1,2, and 3 months of ranibizumab treatment. Three months after intravitreal injection, mean CRT was reduced in the treated eyes from $331.97 \pm 123.62$ to $254.31 \pm 58.75 \mu \mathrm{m}$, while mean CRT in the untreated fellow eyes reduced from $251.07 \pm 40.29$ to $235.45 \pm 36.21 \mu \mathrm{m}$ at the same time. Furthermore, the research has shown that among all transcripts, 3,097 expresses change after the ranibizumab treatment in relation to controls. Among these transcripts, 1,339 were up-regulated, whereas 1,758 were down-regulated. Our results show the potential systemic effects of anti-VEGF therapy for AMD. Moreover, our study indicated different gene expression in peripheral blood mononuclear cells before and after intravitreal ranibizumab treatment.
\end{abstract}

Keywords: ranibizumab, contralateral eye, central retinal thickness, oligonucleotide microarray

\section{Introduction}

Age-related macular degeneration (AMD) is the most common cause of severe, irreversible vision loss in the elderly. ${ }^{1}$ In the last decades, therapies for neovascular AMD treatments were: photodynamic therapy, thermal laser photocoagulation, or transpupillary thermotherapy. Currently, the most widely used treatments for the neovascular exudative form of AMD include intravitreal injections of anti-VEGF agents, such as ranibizumab (Lucentis), aflibercept, or bevacizumab. ${ }^{2}$

Anti-VEGF therapies have been used with increasing frequency to treat other ocular diseases, including diabetic macular edema, ${ }^{3}$ branch retinal vein occlusion, central retinal vein occlusion, ${ }^{4}$ and uveitis. ${ }^{5,6}$

The use of anti-VEGF drugs improved visual prognosis of AMD patients. ${ }^{1}$ It is also suggested that anti-VEGF agents may reach the contralateral eye via the systemic circulation. ${ }^{7,8}$ However, the effects of intravitreal injections of anti-VEGFs 
on untreated contralateral eyes are not well documented. Moreover, systemic side effects of intraocular anti-VEGF therapy for AMD are also not well-known. ${ }^{9}$ Previous studies suggested that this therapy may lead to serious cardiovascular complications. ${ }^{1,10,11}$ On the contrary, Campbell et al observed that anti-VEGF therapy is not associated with increased risk of stroke. ${ }^{12}$ Moreover, there are only few published data regarding gene expression/protein level differences in blood samples of patients with AMD after intravitreal anti-VEGF treatment. ${ }^{13-15}$ Nassar et al suggested that selected cytokine serum levels may be used as biomarkers for AMD or to predict patient responses to anti-VEGF therapies. ${ }^{13}$

The purpose of this study was to evaluate the systemic effects of intravitreal ranibizumab treatment in patients with neovascular AMD. The influence of intravitreal ranibizumab injections on central retinal thickness (CRT) of treated and contralateral untreated eyes, as well as the differences in gene expression patterns in the peripheral blood mononuclear cells (PBMCs) of these patients were analyzed.

\section{Materials and methods Subjects}

The study included 29 patients ( 15 women and 14 men, mean age 73 years, range: 54-86 years) who received ranibizumab because of neovascular AMD diagnosed based on routine ophthalmologic diagnostic procedures (optical coherence tomography [OCT] and fluorescein angiography). All the patients were treated at the Department of Ophthalmology, University Hospital No 5, Medical University of Silesia, Katowice, Poland.

All subjects underwent a complete ophthalmic examination: best-corrected visual acuity using Snellen charts, Goldmann applanation tonometry, indirect biomicroscopy in mydriasis (+78 D lens; Volk Optical, Mentor, OH, USA), OCT (Cirrus HD-OCT 4000, Carl Zeiss Meditec AG, Jena, Germany) and fluorescein angiography (Fundus Camera FF 450 plus IR; Carl Zeiss Meditec AG).

The inclusion criteria for the study group were as follows: choroidal neovascularization (CNV) resulting from AMD, aged $\geq 50$ years, best-corrected visual acuity 0.1 to 0.5 with Snellen chart and no previous CNV therapies, such as anti-VEGF injections, photodynamic, or laser therapies. Patients with uncontrolled, elevated intraocular pressure, glaucomatous optic neuropathy, chronic uveitis, retinal vein occlusion, or other ocular neovascular diseases were excluded from the study. Moreover, patients with a previous history of myocardial infarction or stroke were also excluded. Intravitreal injections were performed by an ophthalmologist, who applied an aseptic technique of the procedure, using infiltration anesthesia in the injection site. The treatment was defined as $0.5 \mathrm{mg}(0.05 \mathrm{~mL})$ of ranibizumab (Lucentis, Novartis International AG, Basel, Switzerland) injected intravitreally in the form of one injection every month during the period of 3 months. The reinjections were dependent on $\mathrm{CNV}$ activity. The study was approved by the Bioethics Committee of the Medical University in Katowice (KNW) in accordance with the Declaration of Helsinki regarding medical research involving human subjects. All patients were informed about the research and signed an informed consent form.

\section{Tissues}

For molecular analysis venous blood samples were collected into ethylenediaminetetraacetic acid-containing tubes before ranibizumab injections and 30 days after the application of three injections of Lucentis at around the same time of day. PMBCs were isolated from $5 \mathrm{~mL}$ specimens derived from each patient by using Ficoll-Conray density gradient centrifugation for 30 minutes at 1,500 rpm at room temperature immediately after blood collection (specific gravity 1.077; Immunobiological Co., Gunma, Japan).

\section{RNA extraction}

Total RNA was extracted using the TRIzol reagent (Thermo Fisher Scientific, Waltham, MA, USA), according to the manufacturer's instructions. RNA extracts were treated with DNase I (RNeasy Mini Kit; Qiagen NV, Venlo, the Netherlands) according to the manufacturer's instructions. The quality of extracts was checked electrophoretically using $0.9 \%$ agarose gel stained with ethidium bromide (Sigma-Aldrich Co., St Louis, MO, USA). The results were analyzed and recorded using the 1D Bas-Sys gel documentation system (Biotech-Fisher, Perth, Australia). Nucleic acid concentration was determined using a GeneQuant II RNA/DNA spectrophotometer (Pharmacia Biotech, Cambridge, UK).

\section{Oligonucleotide microarray analysis}

Eight samples of patients with AMD were collected for microarray analysis (control - three samples; after ranibizumab treatment - five samples) before and after intravitreal ranibizumab injections. The injections were conducted every month during a 3-month period. The analysis of the expression profile of genes was performed using commercially available oligonucleotide microarrays of HG-U133A (Affymetrix, Santa Clara, CA, USA) in accordance with the manufacturer's recommendations, as described previously. ${ }^{16}$ 
Each gene chip contains 22,238 probe sets that correspond to more than 18,400 transcripts and 14,500 well-characterized human genes. Here, approximately $8 \mu \mathrm{g}$ of total RNA were used for the complementary DNA (cDNA) synthesis using SuperScript Choice System (Thermo Fisher Scientific). During the next step, cDNA was used as a template to produce biotin-labeled complementary RNA (cRNA) using BioArray HighYield RNA transcript labeling kit (Enzo Life Sciences, Farmingdale, NY, USA). cRNA was purified on Rneasy Mini Kit columns (Qiagen NV). Next, the biotin-labeled cRNA was fragmented using Sample Cleanup Module (Qiagen NV) and hybridized with the HG-U133A microarray (Affymetrix). The cRNA probes hybridized to oligonucleotide arrays were stained with streptavidin phycoerythrin conjugate and were scanned using GeneArray Scanner G2500A (Agilent Technologies, Santa Clara, CA, USA). The scanned data were processed for signal values using Microarray Suite 5.0 software (Affymetrix). The obtained results were normalized using RMAExpress software (Robust Multichip Average).

\section{Statistical analyses}

Statistical analyses were performed using Statistica 9.0 software (StatSoft, Tulsa, OK, USA), and the level of significance was set at $P<0.05$. Values were expressed as mean and standard deviation. The differences of repeated measures of continuous variables were analyzed with the two-factor analysis of variance (ANOVA) for repeated measures. Paired $t$-test was used to assess the significant differences between CRT at baseline and after ranibizumab treatment in treated and untreated contralateral eyes.

The data from all arrays were analyzed using GeneSpring 12.0 platform (Agilent Technologies) to identify transcriptome differences between the control and ranibizumab treatment groups. The oligonucleotide microarrays of Affymetrix HG-U133A enabled an analysis of 22,283 mRNA transcripts. The normalized data were used to compile a list of genes, the expression of which appeared to be up- or down-regulated by an arbitrary, at least 2-fold, cutoff. A significant differential gene expression was identified by 2.0 -fold change at $P<0.05$ ( $t$-test). The Benjamin-Hochberg false discovery rate multiple test correction was applied whenever applicable. Gene ontology analysis was carried out with the PANTHER 8.0 (Protein Analysis Through Evolutionary Relationships; http://www.pantherdb.org) Classification System database to classify genes based on their biological processes, molecular functions, cellular components, and pathways.

\section{Results}

The differences in CRT between ranibizumab treated and untreated contralateral eyes

In all patients, CRT was measured by OCT in both eyes: before the first dose of treatment was administered (baseline) and again at 1,2, and 3 months after the initiation of treatment in treated eye and untreated contralateral eyes. There was a statistically significant change of CRT between treated and untreated eyes (ANOVA for repeated measures, $P=0.0028$ ). Moreover, there were statistically significant differences in CRT at baseline and after 1, 2, and 3 months of ranibizumab treatment (ANOVA for repeated measures, $P<0.0001$ ) (Figure 1). The mean CRT decreased over time in both groups, with a sharper decrease in the treatment group. The differences in CRT between treated and untreated contralateral eyes means have been narrowing over time (ANOVA for repeated measures, $P=0.0004$ ) (Figure 1).

While mean CRT was significantly reduced in the treated eyes 3 months after intravitreal injection from $331.97 \pm 123.62$ to $254.31 \pm 58.75 \mu \mathrm{m}$ (paired $t$-test, $P<0.0001$ ) (Figure 2A), mean CRT in the untreated fellow eyes reduced significantly from $251.07 \pm 40.29$ to $235.45 \pm 36.21 \mu \mathrm{m} 3$ months later (paired $t$-test, $P=0.0405$ ) (Figure 2B).

\section{The differences in gene expression profile before and after ranibizumab treatment}

During the next step of the research, the gene expression profile was assigned using oligonucleotide microarrays of

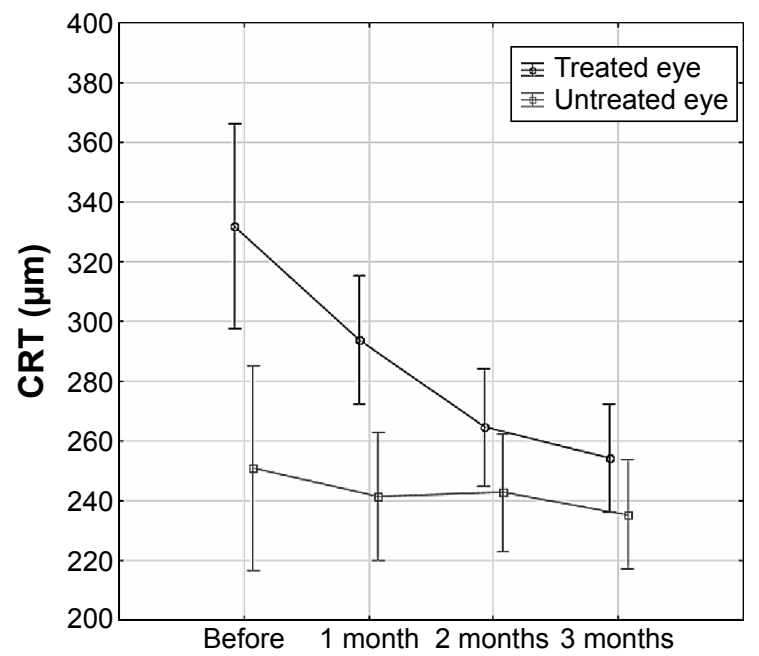

Figure I The differences in central retinal thickness (CRT) over time in treated and untreated contralateral eyes.

Note: Data presented as mean with $95 \% \mathrm{Cl}, P<0.05$, ANOVA for repeated measures.

Abbreviations: $\mathrm{Cl}$, confidence interval; ANOVA, analysis of variance. 
A

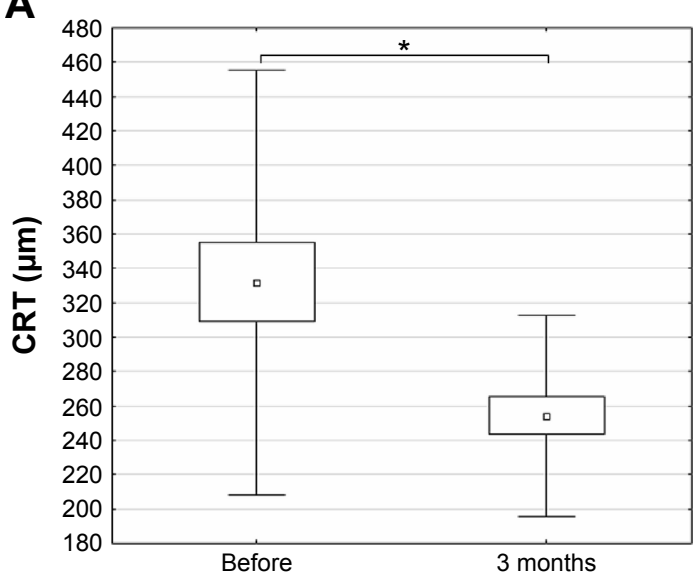

B

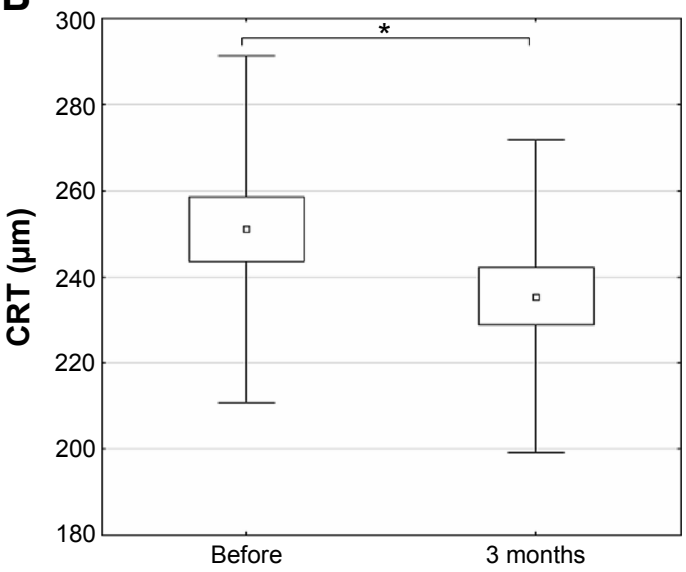

口 Mean $\square$ Mean \pm SE I Mean \pm SD

Figure 2 The central retinal thickness (CRT) measured by optical coherence tomography before the first dose of treatment and 3 months after the initiation of treatment in treated and untreated contralateral eyes.

Notes: (A) Treated and (B) untreated contralateral eyes. Box and whisker plots present mean $\pm \mathrm{SE}$ and $\mathrm{SD}$ of central retinal thickness; $* P<0.05$, paired $t$-test.

Abbreviations: SE, standard error; SD, standard deviation.

Affymetrix HG-U133A, enabling analysis of 22,283 mRNA transcripts. The expression of genes was compared in PBMCs of AMD patients before and after ranibizumab treatment. Among all transcripts, 3,097 for 2,806 genes expressed more than 2-fold statistically significant change after ranibizumab treatment in relation to controls (Table 1). Among these transcripts, 1,339 for 1,137 genes were up-regulated, whereas 1,758 for 1,669 genes were down-regulated. Gene ontology analysis identified 14 subgroups for differentially expressed genes at $P<0.05$ based on biological processes (Figure 3A), ten subgroups based on molecular functions (Figure 3B), and seven subgroups based on cellular components (Figure 3C). In the last part of the study, PANTHER analysis revealed several functional categories that were significantly enriched in statistically differentially expressed gene set compared to the entire National Center for Biotechnology Information reference list of human genome based on biological processes, molecular functions, and cellular components of these genes (Table 2). Moreover, PANTHER pathway analysis revealed that differentially up-regulated genes were enriched for several molecular pathways, including CCKR signaling map ( 21 genes), T-cell activation (13 genes), ubiquitin proteasome pathways (eleven genes), p53 pathways (12 genes), glycolysis (six genes), integrin signaling pathway (19 genes), apoptosis signaling pathway (14 genes), inflammation mediated by chemokine and cytokine signaling pathway (23 genes), gonadotropin releasing hormone receptor pathway (21 genes), cell cycle (five genes), cytoskeletal regulation by Rho GTPase (eleven genes), pentose phosphate pathway (three genes), oxidative stress response (five genes), p38 MAPK pathway (six genes), angiotensin II-stimulated signaling through $\mathrm{G}$ proteins and beta-arrestin (six genes), fructose galactose metabolism (three genes), Ras pathways (nine genes), cadherin signaling pathway (two genes),

Table I Changes in gene expression in PBMCs of AMD patients before and after ranibizumab treatment

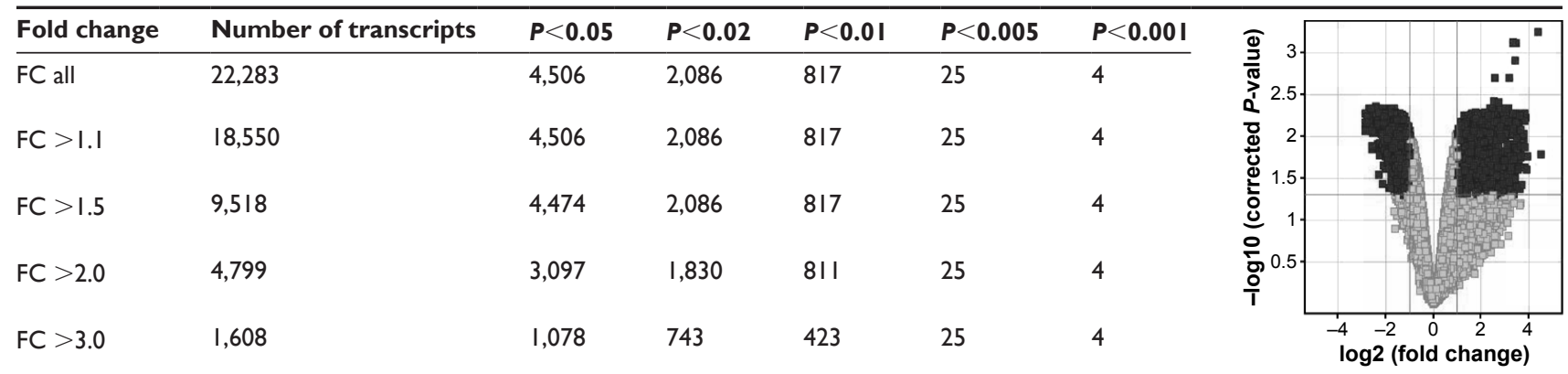

Notes: Volcano plot demonstrates $P$-value and fold change for transcripts which exhibit differential expression in PBMCs of AMD patients before and after ranibizumab treatment. Black indicates differentially expressed genes with $P<0.05$ and $F C>2.0$; gray indicates all genes with $P>0.05$.

Abbreviations: PBMCs, peripheral blood mononuclear cells; AMD, age-related macular degeneration; FC, fold change. 
A

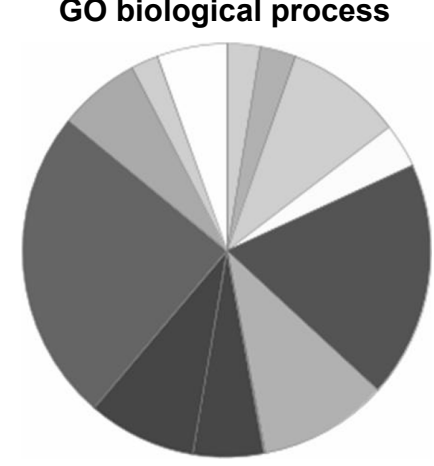

B

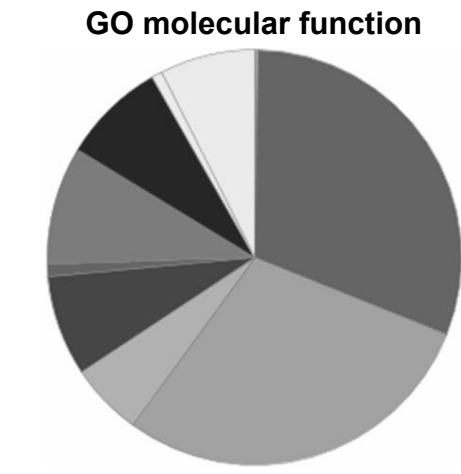

\section{C}

\section{B}

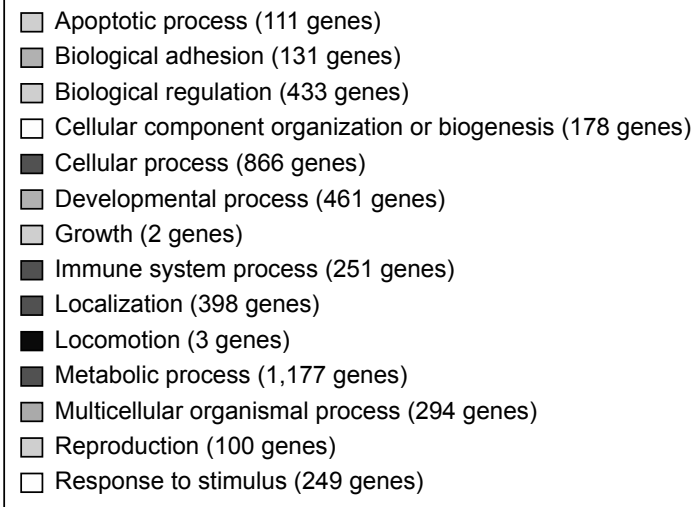

$\square$ Apoptotic process (111 genes)

Biological adhesion (131 genes)

$\square$ Biological regulation (433 genes)

$\square$ Cellular component organization or biogenesis (178 genes)

$\square$ Developmental process (461 genes)

$\square$ Growth (2 genes)

$\square$ Immune system process (251 genes)

$\square$ Localization (398 genes)

Locomotion (3 genes)

$\square$ Reproduction (100 genes)

$\square$ Response to stimulus (249 genes)

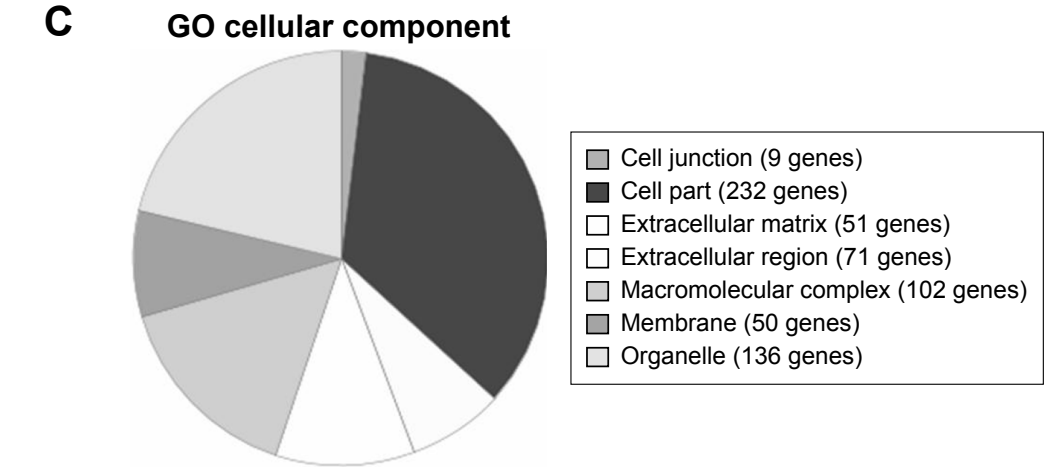

Figure 3 PANTHER classification of differentially expressed genes.

Notes: Based on biological processes (A), molecular functions (B), and cellular components (C).

Abbreviations: PANTHER, Protein Analysis Through Evolutionary Relationships; GO, gene ontology.

cholesterol biosynthesis (three genes), axon guidance mediated by netrin (five genes), isoleucine biosynthesis (two genes), and B-cell activation (seven genes).

In turn, molecular pathways that were significantly enriched in the list of down-regulated genes included cadherin signaling pathways (26 genes), TGF $\beta$ signaling pathway (17 genes), 5HT2 type receptor mediated signaling pathway (eleven genes), gonadotropin releasing hormone receptor pathway (29 genes), 5HT3 type receptor mediated signaling pathway (six genes), 5HT1 type receptor mediated signaling pathway (eight genes), heterotrimeric
G-protein signaling pathway-Gi alpha and Gs alpha mediated pathway (19 genes), CCKR signaling map (22 genes), endothelin signaling pathway (13 genes), 5HT4 type receptor mediated signaling pathway (five genes), 5-hydroxytryptamine degradation (three genes), integrin signaling pathway (21 genes), angiogenesis (18 genes), Wnt signaling pathway (31 genes), de novo purine biosynthesis (seven genes), heterotrimeric G-protein signaling pathway-Gq alpha and Go alpha mediated pathway (14 genes), EGF receptor signaling pathway (15 genes), and oxidative stress response (five genes). 
Table 2 PANTHER classification of biological processes, molecular functions, and cellular components significantly enriched in the set of differentially expressed genes

\begin{tabular}{|c|c|c|c|c|c|}
\hline Biological process & $\begin{array}{l}\text { Number of genes } \\
\text { (observed/expected) }\end{array}$ & $P$-value & Biological process & $\begin{array}{l}\text { Number of genes } \\
\text { (observed/expected) }\end{array}$ & $P$-value \\
\hline Metabolic process & I,I $172 / 925$ & $<0.0001$ & Biological regulation & $431 / 349$ & 0.0005 \\
\hline Cellular process & $865 / 639$ & $<0.0001$ & lon transport & $115 / 74$ & 0.0008 \\
\hline Primary metabolic process & $986 / 771$ & $<0.0001$ & $\begin{array}{l}\text { Cellular component } \\
\text { organization }\end{array}$ & $164 / 114$ & 0.0009 \\
\hline Developmental process & $460 / 306$ & $<0.000$ I & RNA splicing & $56 / 29$ & 0.0012 \\
\hline Cell communication & $486 / 346$ & $<0.0001$ & $\begin{array}{l}\text { RNA splicing, via } \\
\text { transesterification reactions }\end{array}$ & $56 / 29$ & 0.0012 \\
\hline System development & $281 / 177$ & $<0.0001$ & Vesicle-mediated transport & $144 / 100$ & 0.0024 \\
\hline Protein metabolic process & $426 / 302$ & $<0.0001$ & Synaptic transmission & $75 / 45$ & 0.0034 \\
\hline $\begin{array}{l}\text { Multicellular organismal } \\
\text { process }\end{array}$ & $294 / 193$ & $<0.0001$ & Endocytosis & $72 / 43$ & 0.0045 \\
\hline $\begin{array}{l}\text { Single-multicellular organism } \\
\text { process }\end{array}$ & $294 / 193$ & $<0.0001$ & $\begin{array}{l}\text { Cellular protein modification } \\
\text { process }\end{array}$ & $177 / 129$ & 0.0050 \\
\hline System process & $251 / 159$ & $<0.0001$ & $\begin{array}{l}\text { mRNA splicing, via } \\
\text { spliceosome }\end{array}$ & $67 / 40$ & 0.0076 \\
\hline Localization & $397 / 283$ & $<0.0001$ & $\begin{array}{l}\text { Nucleobase-containing } \\
\text { compound metabolic process }\end{array}$ & $452 / 379$ & 0.0080 \\
\hline Transport & $387 / 275$ & $<0.000$ I & Angiogenesis & $49 / 26$ & 0.0102 \\
\hline Neurological system process & $203 / 130$ & $<0.0001$ & Cellular defense response & $69 / 42$ & 0.0109 \\
\hline Nervous system development & $169 / 108$ & $<0.0001$ & Cell death & $110 / 75$ & 0.0135 \\
\hline Translation & $85 / 44$ & $<0.0001$ & Apoptotic process & $110 / 75$ & 0.0135 \\
\hline Mesoderm development & $162 / 103$ & $<0.0001$ & Death & $110 / 75$ & 0.0150 \\
\hline $\begin{array}{l}\text { Intracellular protein } \\
\text { transport }\end{array}$ & $208 / 142$ & $<0.0001$ & Reproduction & $99 / 66$ & 0.0162 \\
\hline Ectoderm development & $153 / 98$ & $<0.0001$ & $\begin{array}{l}\text { Negative regulation of } \\
\text { apoptotic process }\end{array}$ & $39 / 20$ & 0.0207 \\
\hline Cell-cell signaling & $143 / 90$ & $<0.0001$ & Heart development & $47 / 26$ & 0.0211 \\
\hline Protein transport & $208 / 144$ & $<0.0001$ & Visual perception & $56 / 33$ & 0.0218 \\
\hline Response to stimulus & $248 / 179$ & $<0.0001$ & Muscle organ development & $68 / 42$ & 0.0232 \\
\hline Cation transport & $107 / 64$ & $<0.0001$ & Cell cycle & $196 / 150$ & 0.0257 \\
\hline $\begin{array}{l}\text { Cellular component } \\
\text { morphogenesis }\end{array}$ & $113 / 69$ & 0.0001 & $\begin{array}{l}\text { Neuron-neuron synaptic } \\
\text { transmission }\end{array}$ & $23 / 10$ & 0.0375 \\
\hline $\begin{array}{l}\text { Anatomical structure } \\
\text { morphogenesis }\end{array}$ & $119 / 74$ & 0.0001 & $\begin{array}{l}\text { Regulation of biological } \\
\text { process }\end{array}$ & $287 / 234$ & 0.0415 \\
\hline $\begin{array}{l}\text { Cellular component } \\
\text { organization or biogenesis }\end{array}$ & $177 / 122$ & 0.0002 & Gamete generation & $86 / 57$ & 0.0435 \\
\hline Immune system process & $250 / 186$ & 0.0004 & & & \\
\hline Molecular function & & & Molecular function & & \\
\hline Binding & $810 / 637$ & $<0.0001$ & $\begin{array}{l}\text { Cation transmembrane } \\
\text { transporter activity }\end{array}$ & $71 / 40$ & 0.0006 \\
\hline Catalytic activity & $759 / 594$ & $<0.000$ I & RNA binding & $106 / 69$ & 0.0021 \\
\hline Structural molecule activity & $218 / 135$ & $<0.0001$ & Nucleic acid binding & $429 / 356$ & 0.0039 \\
\hline $\begin{array}{l}\text { Structural constituent of } \\
\text { ribosome }\end{array}$ & $60 / 22$ & $<0.0001$ & $\begin{array}{l}\text { Hydrogen ion transmembrane } \\
\text { transporter activity }\end{array}$ & $15 / 5$ & 0.0255 \\
\hline Protein binding & $4 \mid 3 / 307$ & $<0.000 \mathrm{I}$ & Ion channel activity & $62 / 38$ & 0.0316 \\
\hline $\begin{array}{l}\text { Transmembrane transporter } \\
\text { activity }\end{array}$ & $185 / 116$ & $<0.0001$ & Oxidoreductase activity & $99 / 68$ & 0.0344 \\
\hline Transporter activity & $192 / 123$ & $<0.0001$ & mRNA binding & $56 / 34$ & 0.0378 \\
\hline Receptor binding & $163 / 109$ & $<0.0001$ & $\begin{array}{l}\text { Structural constituent of } \\
\text { Cytoskeleton }\end{array}$ & $|26 / 9|$ & 0.0436 \\
\hline Receptor activity & $230 / 169$ & 0.0004 & & & \\
\hline Cellular component & & & Cellular component & & \\
\hline Intracellular & $213 / 154$ & $<0.0001$ & Macromolecular complex & $101 / 70$ & 0.0085 \\
\hline Cell part & $230 / 171$ & 0.0002 & Actin cytoskeleton & $64 / 42$ & 0.0311 \\
\hline Ribonucleoprotein complex & $31 / 14$ & 0.0040 & & & \\
\hline
\end{tabular}

Abbreviation: PANTHER, Protein Analysis Through Evolutionary Relationships. 


\section{Discussion}

The determination of systemic effects of intravitreal ranibizumab injections seems to be important. ${ }^{17}$ Therefore, this report focused on effects of intravitreal ranibizumab injections in patients with neovascular AMD on CRT both in treated and contralateral untreated eyes. Moreover, differences in the gene expression pattern in the PBMCs of patients with AMD after intravitreal injections of ranibizumab were revealed.

In our study, the mean CRT decreased in treated eye and untreated contralateral eye in patients with AMD 3 months after intravitreal injections of ranibizumab, with a sharper decrease in the treatment group. Many previous studies indicated that intravitreal injections of ranibizumab caused a significant reduction of CRT in treated eyes of patients with AMD. ${ }^{18-23}$ However, the possibility of ranibizumab influence on the untreated eye still needs an explanation. Similar to our results, Wu and Sadda and Rouvas et al observed that intravitreal ranibizumab injections had therapeutic effects on the contralateral, un-injected eyes in patients with neovascular AMD. ${ }^{8,24}$ Other authors also reported an effect of ranibizumab on the fellow eye of patients with various ocular diseases. ${ }^{25-27}$ Acharya et al revealed a therapeutic effect on untreated contralateral eyes of patients after the third intravitreal dose of $0.5 \mathrm{mg}$ ranibizumab but with bilateral uveitis-related cystoid macular edema. ${ }^{7}$ Similar to our results, these authors observed a reduction in CRT in treated and contralateral untreated eyes. However, the limitation of Acharya et al's study is the small sample size. Likewise, Al-Dhibi and Khan revealed a bilateral reduction of uveitic cystoid macular edema following unilateral intravitreal bevacizumab injection in an 8-year-old child. ${ }^{28}$ In turn, Sharma et al observed that an intravitreal dexamethasone implantation also seems to have a bilateral effect after unilateral injection in a 54-year-old patient with macular edema. ${ }^{29}$ In another study, Hosseini et al observed that intravitreal injection of bevacizumab significantly changed ocular hemodynamic parameters of both the injected and the untreated fellow eyes of AMD patients..$^{30}$ It seems that this effect may be due to systemic spread of bevacizumab after intravitreal injections.

The decrease in CRT in the contralateral eyes may suggest that intravitreal injections of anti-VEGF agents can have systemic effects. It is known that after intravitreal injections bevacizumab can be detected in higher serum concentrations than ranibizumab and also has a systemically longer halflife. ${ }^{31,32} \mathrm{Xu}$ et al revealed that ranibizumab serum half-life is only approximately 2 hours. One reason for this may be that ranibizumab, an antibody fragment, lacks an Fc domain. ${ }^{33}$
However, pharmacokinetics and bioavailability of ranibizumab are not yet fully known. Previous animal studies revealed small amounts of bevacizumab and ranibizumab in the serum and in the untreated contralateral eye after intravitreal administration. ${ }^{34,35}$ Moreover, Christoforidis et al demonstrated in an animal model that anti-VEGF agent intravitreal injections can have an influence on the cutaneous wound healing. ${ }^{36,37}$ However, only few published reports suggested that low serum levels of anti-VEGF agents may induce a therapeutic effect in the fellow eye of patients. ${ }^{7,8,24,28}$ Additionally, the disruption of blood-retinal barrier in retinal diseases can also increase systemic absorption of anti-VEGF agents after intravitreal injections. ${ }^{7,24}$

Another major issue related to anti-VEGF agents is understanding the molecular mechanism of action of these drugs. Golan et al, in their in vitro study, suggested that anti-VEGF agents may have an influence on gene expression involved in VEGF signaling pathways in different ways..$^{38}$ Therefore, the second part of this study focused on assessing the gene expression profile in PMBCs in AMD patients before and after intravitreal administration of ranibizumab. When we were launching our study there were only few published data regarding gene expression/protein level differences in blood samples of patients with AMD. ${ }^{13-15}$ Mo et al determined serum cytokine levels in patients with AMD and suggested that IFN- $\gamma$-inducible protein-10 and eotaxin may be early biomarkers in this disease. ${ }^{39}$ In turn, Falk et al did not observe significant differences in the blood expression levels of chemokine receptor CCR3 and chemokine CCL11 in patients with neovascular AMD. ${ }^{15}$ Moreover, these authors suggested that intravitreal injections of ranibizumab do not cause systemic alterations of expression of analyzed genes. In contrast, our results revealed changed expression of 3,097 transcripts after ranibizumab treatment. Among all these transcripts, 1,339 were up-regulated, whereas 1,758 were down-regulated. Similarly, Dabir et al, using microarray technique, analyzed systemic gene expression profile but in patients with diabetic macular edema. ${ }^{40}$ These authors revealed that five genes were up-regulated and 105 genes were down-regulated among all studied groups, including diabetic, treatment responder, and treatment non-responder groups. Moreover, there was only one gene up-regulated between the diabetic and treatment responder groups. These authors also suggested that systemic levels of selected genes may be used to classify the treatment responders and non-responders. In addition, classification of differentially expressed genes based on functional category and pathways revealed that these genes play an important role in cancer, 
metabolism, ECM-receptor interaction, tricarboxylic acid cycle, retinol metabolism, TGF- $\beta$ metabolism, VEGF pathway, cell adhesion molecules, p53 signaling, Jak-Stat signaling, and MAPKs pathways. ${ }^{40}$ Similarly, our results revealed that differentially expressed genes before and after ranibizumab treatment in PBMCs of AMD patients play an important role in many of the aforementioned pathways and biological processes, including cellular, metabolic, cell communication, cell-cell signaling, cell adhesion, immune system, and angiogenesis.

In another study, Nassar et al determined levels of many serum cytokines in patients with AMD before and after ranibizumab treatment. ${ }^{13}$ These authors showed that IL-17 and TNF- $\alpha$ levels statistically significantly differ among patients with improvement, no change, and deterioration of CRT after anti-VEGF treatment, respectively. In turn, previous studies revealed that there were no statistically significant differences between serum/plasma VEGF concentrations before and after intravitreal ranibizumab injection measured by enzyme-linked immunosorbent assay. ${ }^{41-43}$ However, the slightly increased serum VEGF concentration in 1 week after ranibizumab treatment may suggest systemic effects of intraocular anti-VEGF therapy. ${ }^{41}$ On the contrary, other authors observed a reduced VEGF level in serum of AMD patients after bevacizumab intravitreal injections. ${ }^{31,44}$ Similarly, our results revealed inhibition of VEGF expression among differentially expressed genes in PBMCs of intravitreal ranibizumab treatment patients. In conclusion, our results suggest the potential systemic effects of anti-VEGF therapy for AMD. Our study revealed the reduction of CRT after intravitreal ranibizumab injections in patients with neovascular AMD both in treated and contralateral untreated eye. ${ }^{45}$ Moreover, our study indicated a differential gene expression in PMBCs obtained from AMD patients before and after the intravitreal ranibizumab treatment. These results may contribute to a better understanding of the molecular mechanisms involved in the drug response of patients with AMD. Moreover, the differentiating genes determined by oligonucleotide microarray technique may also be the target of further research. Unfortunately, the major limitation of our study is a relatively small number of samples. Therefore, there is a need to study a larger population and carry out further analysis in order to better clarify the systemic effects of anti-VEGF-agents. Moreover, detailed examination of AMD therapy will also help to identify better treatment strategies for this disease.

\section{Acknowledgment}

This research was supported in part by PL-Grid Infrastructure (http://www.plgrid.pl/en).

\section{Disclosure}

The authors declare that there are no conflicts of interest.

\section{References}

1. Cheung CM, Wong TY. Is age-related macular degeneration a manifestation of systemic disease? New prospects for early intervention and treatment. J Intern Med. 2014;276(2):140-153.

2. Emerson MV, Lauer AK. Current and emerging therapies for the treatment of age-related macular degeneration. Clin Ophthalmol. 2008;2(2):377-388.

3. Régnier S, Malcolm W, Allen F, Wright J, Bezlyak V. Efficacy of antiVEGF and laser photocoagulation in the treatment of visual impairment due to diabetic macular edema: a systematic review and network metaanalysis. PLoS One. 2014;9(7):e102309.

4. Brown DM, Wykoff CC, Wong TP, et al. Ranibizumab in preproliferative (ischemic) central retinal vein occlusion: the rubeosis anti-VEGF (RAVE) trial. Retina. 2014;34(9):1728-1735.

5. Couturier A, Bousquet E, Zhao M, et al. Anti-vascular endothelial growth factor acts on retinal microglia/macrophage activation in a rat model of ocular inflammation. Mol Vis. 2014;20:908-920.

6. Ciulla TA, Rosenfeld PJ. Anti-vascular endothelial growth factor therapy for neovascular ocular diseases other than age-related macular degeneration. Curr Opin Ophthalmol. 2009;20(3):166-174.

7. Acharya NR, Sittivarakul W, Qian Y, Hong KC, Lee SM. Bilateral effect of unilateral ranibizumab in patients with uveitis-related macular edema. Retina. 2011;31(9):1871-1876.

8. Wu Z, Sadda SR. Effects on the contralateral eye after intravitreal bevacizumab and ranibizumab injections: a case report. Ann Acad Med Singapore. 2008;37(7):591-593.

9. Lim LS, Cheung CM, Mitchell P, Wong TY. Emerging evidence concerning systemic safety of anti-VEGF agents - should ophthalmologists be concerned? Am J Ophthalmol. 2011;152(3):329-331.

10. Hwang DJ, Kim YW, Woo SJ, Park KH. Comparison of systemic adverse events associated with intravitreal anti-VEGF injection: ranibizumab versus bevacizumab. J Korean Med Sci. 2012;27(12):1580-1585.

11. Wong TY. Age-related macular degeneration and cardiovascular disease in the era of anti-vascular endothelial growth factor therapies. Am J Ophthalmol. 2009;148(3):327-329.

12. Campbell RJ, Bell CM, Paterson JM, et al. Stroke rates after introduction of vascular endothelial growth factor inhibitors for macular degeneration: a time series analysis. Ophthalmology. 2012;119(8):1604-1608.

13. Nassar K, Grisanti S, Elfar E, Lüke J, Lüke M, Grisanti S. Serum cytokines as biomarkers for age-related macular degeneration. Graefes Arch Clin Exp Ophthalmol. 2015;253(5):699-704.

14. Nita M, Michalska-Małecka K, Mazurek U, et al. Influence of ranibizumab treatment on the extracellular matrix in patients with neovascular age-related macular degeneration. Med Sci Monit. 2014;20: 875-883.

15. Falk MK, Singh A, Faber C, Nissen MH, Hviid T, Sørensen TL. Blood expression levels of chemokine receptor CCR3 and chemokine CCL11 in age-related macular degeneration: a case-control study. $B M C$ Ophthalmol. 2014;14:22

16. Orchel J, Witek L, Kimsa M, et al. Expression patterns of kinindependent genes in endometrial cancer. Int J Gynecol Cancer. 2012; 22(6):937-944.

17. Avery RL. What is the evidence for systemic effects of intravitreal antiVEGF agents, and should we be concerned? Br J Ophthalmol. 2014; 98 Suppl 1:i7-i10.

18. Chavan R, Panneerselvam S, Adhana P, Narendran N, Yang Y. Bilateral visual outcomes and service utilization of patients treated for 3 years with ranibizumab for neovascular age-related macular degeneration. Clin Ophthalmol. 2014;8:717-723.

19. Canan H, Sızmaz S, Altan-Yaycığlu R, Sarı̈ürk C, Yılmaz G. Visual outcome of intravitreal ranibizumab for exudative age-related macular degeneration: timing and prognosis. Clin Interv Aging. 2014;9:141-145. 
20. Moisseiev E, Katz G, Moisseiev J, et al. Switching treatment for neovascular age-related macular degeneration from bevacizumab to ranibizumab: who is likely to benefit from the switch? Retina. 2015; 35(7):1323-1330.

21. CATT Research Group; Martin DF, Maguire MG, et al. Ranibizumab and bevacizumab for neovascular age-related macular degeneration. N Engl J Med. 2011;364(20):1897-1908.

22. Subramanian ML, Abedi G, Ness S, et al. Bevacizumab vs ranibizumab for age-related macular degeneration: 1-year outcomes of a prospective, doublemasked randomised clinical trial. Eye (Lond). 2010;24(11):1708-1715.

23. Krebs I, Schmetterer L, Boltz A, et al. A randomised double-masked trial comparing the visual outcome after treatment with ranibizumab or bevacizumab in patients with neovascular age-related macular degeneration. Br J Ophthalmol. 2013;97(3):266-271.

24. Rouvas A, Liarakos VS, Theodossiadis P, et al. The effect of intravitreal ranibizumab on the fellow untreated eye with subfoveal scarring due to exudative age-related macular degeneration. Ophthalmologica. 2009;223(6):383-389.

25. Lüke J, Nassar K, Grisanti S, Lüke M. Regression of rubeosis in the fellow eye after intravitreal ranibizumab injection. Graefes Arch Clin Exp Ophthalmol. 2013;251(1):371-373.

26. Rotsos T, Symeonidis C, Triantafillopoulou I, Kanellopoulos S, Kouris A. Significant reduction of diabetic macular edema following intravitreal ranibizumab injection in the fellow eye. Int Ophthalmol. 2014 34(6):1271-1274.

27. Pescosolido N, Fazio S, Rusciano D. Therapeutic improvement in the contralateral eye after ranibizumab intravitreal treatment in a patient affected by bilateral subfoveal choroidal neovascularization. JSM Biotechnol Bioeng. 2014;2(2):1038.

28. Al-Dhibi $\mathrm{H}$, Khan AO. Bilateral response following unilateral intravitreal bevacizumab injection in a child with uveitic cystoid macular edema. J AAPOS. 2009;13(4):400-402.

29. Sharma A, Sheth J, Madhusudan RJ, Sundaramoorthy SK. Effect of intravitreal dexamethasone implant on the contralateral eye: a case report. Retin Cases Brief Rep. 2013;7(3):217-219.

30. Hosseini H, Lotfi M, Esfahani MH, et al. Effect of intravitreal bevacizumab on retrobulbar blood flow in injected and uninjected fellow eyes of patients with neovascular age-related macular degeneration. Retina. 2012;32(5):967-971.

31. Avery RL, Castellarin AA, Steinle NC, et al. Systemic pharmacokinetics following intravitreal injections of ranibizumab, bevacizumab or aflibercept in patients with neovascular AMD. Br J Ophthalmol. 2014; 98(12):1636-1641.

32. Moisseiev E, Waisbourd M, Ben-Artsi E, et al. Pharmacokinetics of bevacizumab after topical and intravitreal administration in human eyes. Graefes Arch Clin Exp Ophthalmol. 2014;252(2):331-337.
33. Xu L, Lu T, Tuomi L, et al. Pharmacokinetics of ranibizumab in patients with neovascular age-related macular degeneration: a population approach. Invest Ophthalmol Vis Sci. 2013;54(3):1616-1624.

34. Bakri SJ, Snyder MR, Reid JM, Pulido JS, Ezzat MK, Singh RJ. Pharmacokinetics of intravitreal bevacizumab (Avastin). Ophthalmology. 2007;114(5):855-859.

35. Gaudreault J, Fei D, Rusit J, Suboc P, Shiu V. Preclinical pharmacokinetics of Ranibizumab (rhuFabV2) after a single intravitreal administration. Invest Ophthalmol Vis Sci. 2005;46(2):726-733.

36. Christoforidis J, Ricketts R, Pratt C, et al. The effect of intravitreal anti-VEGF agents on peripheral wound healing in a rabbit model. Clin Ophthalmol. 2012;6:61-69.

37. Christoforidis JB, Wang J, Jiang A, et al. The effect of intravitreal bevacizumab and ranibizumab on cutaneous tensile strength during wound healing. Clin Ophthalmol. 2013;7:185-191.

38. Golan S, Entin-Meer M, Semo Y, et al. Gene profiling of human VEGF signaling pathways in human endothelial and retinal pigment epithelial cells after anti VEGF treatment. BMC Res Notes. 2014;7:617.

39. Mo FM, Proia AD, Johnson WH, Cyr D, Lashkari K. Interferon gamma-inducible protein-10 (IP-10) and eotaxin as biomarkers in age-related macular degeneration. Invest Ophthalmol Vis Sci. 2010; 51(8):4226-4236.

40. Dabir SS, Das D, Nallathambi J, Mangalesh S, Yadav NK, Schouten JS. Differential systemic gene expression profile in patients with diabetic macular edema: responders versus nonresponders to standard treatment. Indian J Ophthalmol. 2014;62(1):66-73.

41. Wang X, Sawada T, Sawada O, Saishin Y, Liu P, Ohji M. Serum and plasma vascular endothelial growth factor concentrations before and after intravitreal injection of aflibercept or ranibizumab for age-related macular degeneration. Am J Ophthalmol. 2014;158(4):738-744.

42. Carneiro AM, Costa R, Falcão MS, et al. Vascular endothelial growth factor plasma levels before and after treatment of neovascular agerelated macular degeneration with bevacizumab or ranibizumab. Acta Ophthalmol. 2012;90(1):e25-e30.

43. Zehetner C, Kralinger MT, Modi YS, et al. Systemic levels of vascular endothelial growth factor before and after intravitreal injection of aflibercept or ranibizumab in patients with age-related macular degeneration: a randomised, prospective trial. Acta Ophthalmol. 2015;93(2):e154-e159.

44. Wang D, Choi KS, Lee SJ. Serum concentration of vascular endothelial growth factor after bilateral intravitreal injection of bevacizumab. Korean J Ophthalmol. 2014;28(1):32-38.

45. Sizmaz S, Kucukerdonmez C, Kal A, Pinarci EY, Canan H, Yilmaz G. Retinal and choroidal thickness changes after single anti-VEGF injection in neovascular age-related macular degeneration: ranibizumab vs bevacizumab. Eur J Ophthalmol. 2014;24(6):904-910.
Clinical Interventions in Aging

\section{Publish your work in this journal}

Clinical Interventions in Aging is an international, peer-reviewed journal focusing on evidence-based reports on the value or lack thereof of treatments intended to prevent or delay the onset of maladaptive correlates of aging in human beings. This journal is indexed on PubMed Central, MedLine,
CAS, Scopus and the Elsevier Bibliographic databases. The manuscript management system is completely online and includes a very quick and fair peer-review system, which is all easy to use. Visit http://www.dovepress. com/testimonials.php to read real quotes from published authors. 